a portion (and it may be a diminutive quantity) locally detached from the main stream, or a feeder dropping into the main stream from steep, rocky sides. This is the primary cause. But along with the presence of a graving machine in the falling waters, to explain the making of the fonts a concurrent cause is necessary, as otherwise they should be looked for anywhere and everywhere on rapid descents. The conducive condition is the coincidence of falling waters with a reakness of the rock, such as an intersection of the division planes or fissures. I have secured a specimen font, Io inches deep and 12 inches width across the bell-shaped mouth, in compact siliceous rock graven by a diminutive shoot of the main stream running down the depres. sion which generally marks the edge of a division plane till it reached an intersection; at the intersection it graved a font, and issuing from this went on to the next, and there graved another (see sketch; Fig. I). The stream, flowing round and kept up by a bed of rock dipping approximately in the direction of the current, overflows in flood-time, or generally except in dry summer weather, down the fissure A B; at the intersections the fonts were graven, and the water on leaving the lower one runs along the edge of a superposed bed. We are now bound to seek a limiting condition, as otherwise almost every pool into which there

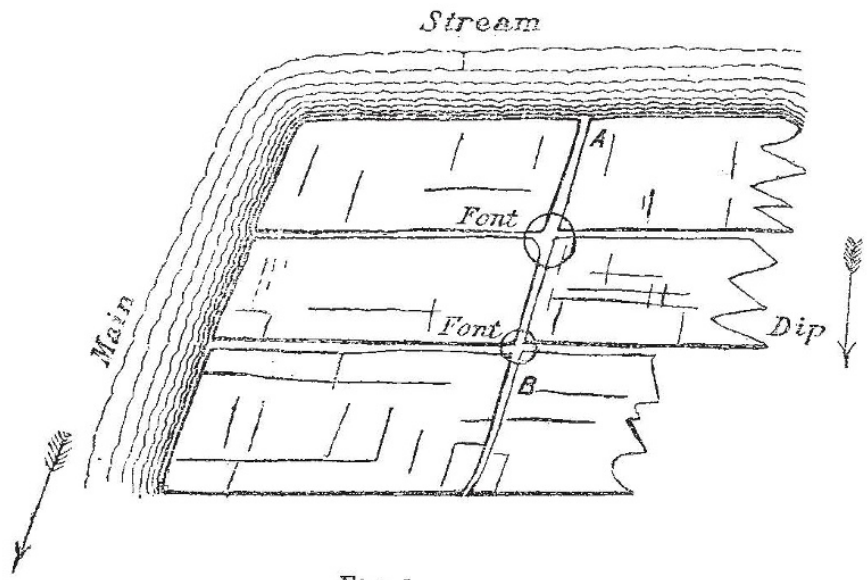

Fig.1

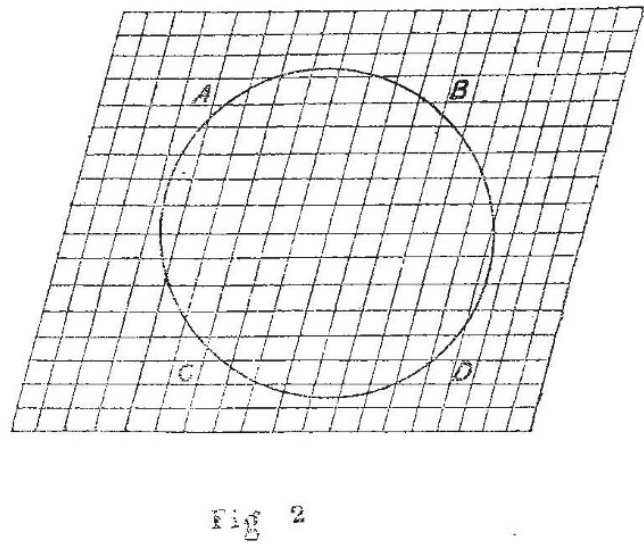

is a waterfall might reasonably be expected to be a font. The limiting cause is the relation between the size of the blocks into which the rock is divided and the graving power of the falling waters. If the waterfall is sufficient to grave a font of over a certain size in rocks broken by planes into blocks of a certain size, the consequence is that the whole blocks or blocks by frag. ments will be broken away, and the walls will be the divisional planes of the rock and lose altogether the font shape, as is wholly or partially the case under our larger waterfalls owing to the "pigmy plan" on which our (Slievardagh) rocks are broken up by planes. Fig. 2 will explain the meaning I wish to convey.

\title{
The Good Time Begun
}

THE following has just been received from a nephew in the Bombay Presidency, who, after speaking generally of a tremendous gale from the south-west, with heavy sea, fog, \&c., all along the West Coast, writes thus more particularly :-

"That same mist and rain have been for the present the saving of this Presidency from another famine. It (the rain) has been general and heavy all over the country, and was just in time to save the crops, which were fast perishing from lack of moisture. If we have a little more this month and another good fall in September, we shall be quite safe; and I do trust we shall not be disappointed, as another year-the fourth in succession-of scarcity would well nigh make 'the bankruptcy of India,' so far as Bombay is concerned, a sad fact."

You will note the appearance of this desiderated Indian rain coming from the same direction as the chief part of that which has been delnging our own country; but which $\mathrm{Mr}$. Campbell shrewdly attributed, in NATURE, vol. xx. p. 403, to the sun recovering his forces and beginning already to shine, after bis recent languid, spotless years, with increased radiation on the great oceans of the south.

15, Royal Terrace, Edinburgh, August 30

\section{Insect-Swarms}

IN answer to Mr. Hawkshaw's question whether any one had seen a flight of moths and butterfties in England similar to the one he observed at Trouville on August 12 and 13, I can say that on August 12 I was walking on the Dawlish Warren (a bar of sand stretching across the mouth of the Exe) and noticed a great number of $P$. gamma molhs; they were close to the edge

Suppose the rocks broken by two sets of planes, and there may be many sets and the stratification as well ; now suppose a font graven to the size of the circle; it is plain that this could not have stability, as the blocks at $A, B, C, D$ wonld have come away during the process. But had the font been so small as to take only a portion of any four blocks no discontinuance of the graving action could yet have occurred.

I may add that about 2 feet in width and depth is the size of the largest font I have come upon hitherto.

Earlshill Colliery, Thurles

WILLIAM MORRIS

of the water ; many of them were dead, and the sand hoppers were eating them, but many more were alive and trying to flutter inland, but seemed too weak to do so. I picked up some and carried them to some wild thyme and they began to feed at once. Some of the moths were in good condition but others very much battered. The wind was blowing freshly from the sea at the time. The moths swarmed in the hedges all the way from our honse to the Warren, a distance of four miles, especially on the bramble flowers. There were a great many $V$. cardu $i$ with the moths in the hedges, but none on the beach. A few days afterwards I had a letter from my brother at Dieppe saying there had been a swarm of moths and butterflies there, especially mentioning $P$. gamma and $V$. cardui, but there were also skippers and clouded whites. They swarmed about the town and country and were lying dead on the beach. The swarm of moths and butterflies was also on August 12.

Kenton, near Exeter, August 3 I

\section{Earthquake in Dominica}

A SEVEre shock of earthquake was felt here at I,20 A. x. yesterday (Sunday) the Ioth instant, and at intervals, until $\mathbf{1 . 5}$, there were several tremulous movements of the earth. The noise immediately preceding the first shock reminded me of the clatter which is sometimes heard on board an ocean strikes the steamer in very rough weather, when a heavy sea sty thrown ship, and all the crockery laid out for dinner is suces on the floor of the from the "fiddles" and broken into pieces on the floor of the saloon.

After the first shock there was aises like the discharging or until Y. 30, when subterranean attracted my attention, and then, at 